\title{
Model based decision support system of operating settings for MMAT nozzles
}

\author{
Bradley Keith Fritz ${ }^{1}$, Zbigniew Czaczyk ${ }^{2,1 *}$, Wesley Clint Hoffmann ${ }^{1}$ \\ ${ }^{1}$ USDA-ARS-Aerial Application Technology Research Unit, 3103 F\&B Road, College Station, TX 77845, USA \\ ${ }^{2}$ Poznań University of Life Sciences, Wojska Polskiego 28, 60-637 Poznań, Poland
}

Received: February 26, 2016

Accepted: June 10, 2016

\begin{abstract}
Droplet size, which is affected by nozzle type, nozzle setups and operation, and spray solution, is one of the most critical factors influencing spray performance, environment pollution, food safety, and must be considered as part of any application scenario. Characterizing spray nozzles can be a timely and expensive proposition if the entire operational space (all combinations of spray pressure and orifice size, what influence flow rate) is to be evaluated. This research proposes a structured, experimental design that allows for the development of computational models for droplet size based on any combination of a nozzle's potential operational settings. The developed droplet size determination model can be used as Decision Support System (DSS) for precise selection of sprayer working parameters to adapt to local field scenarios. Five nozzle types (designs) were evaluated across their complete range of orifice size (flow rate*) and spray pressures using a response surface experimental design. Several of the models showed high level fits of the modeled to the measured data while several did not as a result of the lack of significant effect from either orifice size (flow rate*) or spray pressure. The computational models were integrated into a spreadsheet based user interface for ease of use. The proposed experimental design provides for efficient nozzle evaluations and development of computational models that allow for the determination of droplet size spectrum and spraying classification for any combination of a given nozzle's operating settings. The proposed DSS will allow for the ready assessment and modification of a sprayers performance based on the operational settings, to ensure the application is made following recommendations in plant protection products (PPP) labels.
\end{abstract}

Key words: droplet size classification, droplet size determination, DSS, spraying classification, modeling, sprayer adjustment, sprayer operating settings

\section{Introduction}

Ensuring maximum biological efficacy of an agrochemical spray application, while mitigating off-target movement, requires consideration of the setup of the sprayer system. It needs particularly with respect to nozzle selection and operation. Both of which significantly affect the resulting droplet size, which in turn significantly influences spray deposition, biological efficacy, PPP losses (aerial drift, volatilization, ground sediment) (Hewitt 1997a, b; Matthews 2000; Dorr et al. 2013), and residues (Czaczyk and Gnusowski 2007). Through the use of different nozzle types and sprayer operational settings, the generated droplet size spectra can easily be influenced across a wide range of available potential of droplet sizes. These parameters are critically important in providing advice to supporting plant protection (Doble et al. 1985; Gajtkowski 1985; Matthews 2000; Giles et al. 2005; Czaczyk 2013). Knowing the actual atomization characteristics and, particularly, droplet size classification, can be difficult as actual droplet size information is not typically provided by a nozzle manufacturer across large combination of flow rate and operational pressures within a given nozzle type.
The description flow rate* for nozzle designation is more adequate to use, because for air induction nozzles the flow rate is determined at the inlet (diameter). The size of outlet (cross area and geometry) of flat fan nozzles influence the form of spray shape - the spray angle and atomization characteristics (Dorr et al. 2013). The description of orifice size e.g. 02 (i.e. two US liquid gallons per minute at 276 psi pressure) comes from the visiflo system proposed in 1983 by Spraying Systems Co. ${ }^{\circledR}$. For the agricultural nozzles exist since 2005 an international standard in metric units ISO 10625 (2005). For the description 02, at $300 \mathrm{kPa}$ pressure, the flow rate is $0.81 \cdot \mathrm{min}^{-1}( \pm 5 \%$ tolerance).

Developing databases of droplet size data and classification for a given nozzle type can be time consuming and expensive given the large number of potential combinations of flow rate* and pressure for any given nozzle (Czaczyk 2012a, b; Douzals 2012; Dorr et al. 2013; Fritz et al. 2014a, b). As an example a typical flat fan type nozzle may have as many as 10 (or in some cases more) flow rate $^{*}$ available, and may have a recommended operational pressure range covering 100 to $800 \mathrm{kPa}$. Were every flow rate* to be tested at each $100 \mathrm{kPa}$ of pressure, 80 treatment 
points would have to be evaluated to provide droplet size data that covered this nozzles full operating range.

Kirk (2007) applied a response surface method (RSM) experimental design, which uses a coded set of treatment combinations from the potential factors influencing atomization phenomenon and droplet size. This original application of the RSM design focused on aerial application spray nozzles whose droplet size was influenced by four primary factors, for a given nozzle type. These included flow rate*, spray pressure, air speed and nozzle orientation. This method used a set of 27 experimental data points that allowed for the development of a second-order regression equation that calculated droplet size based on user-defined specifications of the four main factors (Kirk 2007). This method was further applied to a limited set of ground application spray nozzles used in the United States of America and was shown to provide high levels of fit from the model when compared to independently evaluated tested points (Fritz et al. 2016).

The evaluation of droplet size from agricultural sprays is potentially impacted by the measurement method (Hammond 1981; Tishkoff 1984; Hewitt 1997a) and instrumentation (Dodge 1987) used. While a detailed discussion of these factors is beyond the scope of this work Fritz et al. (2014b), has shown that careful attention to measurement setups and operational settings can lead to droplet size results with inter- and intra-laboratory repeatability and precision. The methods developed in that work are adopted for this study and discussed in greater detail in the methods.

The objective of this work was to evaluate a set of ground nozzles used for agrochemical applications in Poland, using a definitive screening response surface model experimental design to develop predictive droplet size models for each. Further, to evaluate the complete operational space to better understand the spray characteristics of each nozzle tested, and provide to plant protection products (PPP) application advisors as a Decision Support System (DSS) at no cost.

\section{Materials and Methods}

Ground application nozzles were evaluated for droplet size following a definitive screening experimental design. The measured data were fit to a mathematical prediction expression in the form of a response surface. The completed models were integrated into an Excel spreadsheet user interface that provides both droplet size and classification data to the user. Droplet measurement and data analysis methods as well as the nozzles tested and experimental design used are discussed in the following sections.

\section{Definitive screening designs for response surface models}

Five different types of flat fan nozzles (multiple designs) were selected for testing (Table 1). These nozzles produced according standards: ISO 10625 (2005), ISO 8169 (1984) (Czaczyk and Szulc 2012), represent those typically used in Poland for agricultural ground spray applications.
Study conducted on MMAT nozzles, for an optimized use them for crop protection, according requirements of PPP labels. Each nozzle was evaluated over a range of flow rate $^{*}$ and spray pressures, as specified in Table 1 .

All experimental designs were developed and data processing completed using JMP ${ }^{\circledR}$ (Version 11.1.1, 2013 SAS Institute). For all tested nozzles, flow rate* was set in the model as a discrete factor with each flow rate* available set as a level (flow rate* available given in Table 1). Spray pressure was set as a continuous variable with maximum and minimum values as given in Table 1 . The final developed models are only applicable across the range of parameters tested and cannot be extended beyond. Treatment lists for each nozzle are given in Tables $2-6$. Note that there are some treatments that are identical in each treatment list, these are specified by the experimental design and are typically in the center of the operational space and provide for an increased fit of the model. These runs were separated by a different treatment and not analyzed as a continuous set of replications.

\section{Droplet size measurements}

All droplet-sizing measurements were performed at the United States Department of Agriculture (USDA), Agricultural Research Service (ARS) Aerial Application Technology Research Unit's laboratory located in College Station, Texas. A low speed $\left(0.4-8.0 \mathrm{~m} \cdot \mathrm{s}^{-1}\right.$ air speed range) airflow tunnel (1.2 by $1.2 \mathrm{~m}$, by $9.8 \mathrm{~m}$ long) was used to provide concurrent airflow ( $\mathrm{Rh} \sim 70 \%, \mathrm{t} \sim 20^{\circ} \mathrm{C}$ ) to the nozzle. A concurrent airflow of $6.7 \mathrm{~m} \cdot \mathrm{s}^{-1}$ was used (Hewitt 1997a, b - who first determined the wind tunnel speed necessary to mitigate spatial sampling bias) in all nozzle evaluations to minimize spatial sampling errors with the laser diffraction system (Fritz et al. 2012, 2014a). The nozzle positioned upstream of the tunnel exit and $30.5 \mathrm{~cm}$ upstream of the line of measurement. All droplet sizing was conducted using a spray solution of water ( $\mathrm{t} \sim 20^{\circ} \mathrm{C}$ ) with a $0.25 \% \mathrm{v} / \mathrm{v}_{\mathrm{v}}$ of a $90 \%$ non-ionic surfactant (NIS) R-11 ${ }^{\circledR}$ (Wilbur-Ellis, USA) (Miller and Tuck 2005), which resulted in a solution with a dynamic surface tension of $0.050 \mathrm{~N} \cdot \mathrm{m}^{-1}$ (at $20 \mathrm{~ms}$ ) and a shear viscosity of 0.44 $\mathrm{cP}$ (required in ANSI/ASAE S572.1 standard). This solution was fed to the nozzle from a 191 stainless steel pressure tank that was pressurized using an air compressor (Campbell Hausfeld, USA). A pressure regulator was used to adjust air pressure into the tank to vary spray pressure at the nozzle. The spray pressure at the nozzle was controlled at each run with and electronic pressure gauge (PX409-100GUSB, Omega Engineering, Stanford CT).

All droplet size data was measured using a Sympatec HELOS Vario/KR ${ }^{\circledR}$ laser diffraction system (Sympatec $\mathrm{GmbH}$, Clausthal-Zellerfeld, Germany) that was operated using the manufacturer denoted R7 lens which has a dynamic size range of $\varnothing 18-3,500 \mu \mathrm{m}$ across 31 bins. Both the concurrent air stream velocity and the measurement distance were determined from previous work (Fritz et al. 2014a) to minimize spatial sampling error, and are now standard methods at several droplet size laboratories (Fritz et al. 2014b). Evaluation of each treatment consisted of a series of replicated measurements, each of 
which wasone full vertical traverse of the spray plume at a rate of $6.4 \mathrm{~cm} \cdot \mathrm{s}^{-1}$. A sufficient number of replications were made to ensure that the standard deviations of $\mathrm{D}_{\mathrm{v} 0.1}, \mathrm{D}_{\mathrm{v} 0.5}(\mathrm{VMD})$, and $\mathrm{D}_{\mathrm{v} 0.9}$ (the 10, 50 and $90 \%$ volume diameters, VMD - volume median diameter) were within $\pm 5 \%$ of the means (minimum of three replications). Additionally, the percent volume of the spray $\left(\mathrm{V}_{<100}\right)$ contained in droplets of diameter below $\varnothing 100 \mu \mathrm{m}\left(\%_{\text {vol }}\right)$ was also recorded (ASABE 2012; Czaczyk 2013, 2014). Recorded droplet size data is included in Tables 2-6 alongside the nozzle/pressure combinations evaluated.

\section{Droplet size classification}

The reference nozzles, as specified by the ANSI/ASAE S572.1 spray classification standard (ASABE 2009), were evaluated for droplet size as part of this work. The reference used nozzles were a set obtained from Spraying Systems Co. ${ }^{\circledR}$ (Wheaton, IL) that were flow rated to meet the levels specified in the standard. Droplet size measurements were taken for each nozzle at the reference pressures specified (ASABE 2009) [450, 300, 200, 250, 200 and $150 \mathrm{kPa}$ for the 11001, 11003, 11006, 8008, 6510, and 6515 nozzles (ISO 10625), respectively].

Table 1. Nozzles evaluated using the response surface experimental design method and the flow rate* and pressure ranges tested

\begin{tabular}{cccc}
\hline $\begin{array}{c}\text { Nozzle design } \\
(\text { ISO 8169) }\end{array}$ & $\begin{array}{c}\text { Manufacturer } \\
\left(\text { design }^{1}\right)\end{array}$ & $\begin{array}{c}\text { Flow rate* } \\
\text { (ISO 10625) }\end{array}$ & Pressure range [kPa] \\
\hline EZ & MMAT (AI) & 015 to 08 & $100-600$ \\
EZK & MMAT (AI) & 02 to 06 & $100-600$ \\
EZKT & MMAT (AIT) & 02 to 08 & $100-600$ \\
AZ & MMAT (RD) & 015 to 05 & $100-500$ \\
RS & MMAT (FF) & 01 to 20 & $100-500$ \\
\hline
\end{tabular}

${ }^{1}$ design abbreviation: AI - air induction; AIT - AI-twin jet; RD - pre orifice; FF- standard flat fan

Table 2. Definitive screening model treatment list for the EZ nozzle

\begin{tabular}{|c|c|c|c|c|c|c|}
\hline Run number & $\begin{array}{l}\text { Flow } \\
\text { rate }^{*}\end{array}$ & $\begin{array}{c}\text { Pressure } \\
{[\mathrm{kPa}]}\end{array}$ & $\begin{array}{l}\mathrm{D}_{\mathrm{v} 0.1} \\
{[\mu \mathrm{m}]}\end{array}$ & $\begin{array}{l}\mathrm{D}_{\mathrm{v} 0.5} \\
{[\mu \mathrm{m}]}\end{array}$ & $\begin{array}{l}D_{v 0.9} \\
{[\mu \mathrm{m}]}\end{array}$ & $\begin{array}{c}\mathrm{V}_{<100} \\
{\left[\%_{\text {vol }}\right]}\end{array}$ \\
\hline 1 & 015 & 390 & 170 & 384 & 707 & 2.7 \\
\hline 2 & 02 & 600 & 121 & 263 & 484 & 6.3 \\
\hline 3 & 025 & 250 & 158 & 365 & 695 & 3.1 \\
\hline 4 & 03 & 430 & 168 & 376 & 657 & 2.6 \\
\hline 5 & 03 & 430 & 169 & 381 & 681 & 2.6 \\
\hline 6 & 05 & 600 & 171 & 385 & 648 & 2.4 \\
\hline 7 & 06 & 250 & 197 & 439 & 715 & 1.6 \\
\hline 8 & 06 & 430 & 169 & 384 & 642 & 2.7 \\
\hline 9 & 06 & 430 & 183 & 409 & 673 & 2.2 \\
\hline 10 & 08 & 250 & 219 & 491 & 814 & 1.2 \\
\hline 11 & 08 & 600 & 166 & 382 & 653 & 2.8 \\
\hline
\end{tabular}

Table 3. Definitive screening model treatment list for the EZK nozzle

\begin{tabular}{ccccccc}
\hline Run number & Flow rate* & $\begin{array}{c}\text { Pressure } \\
{[\mathrm{kPa}]}\end{array}$ & $\begin{array}{c}\mathrm{D}_{\mathrm{v0} .1} \\
{[\mu \mathrm{m}]}\end{array}$ & $\begin{array}{c}\mathrm{D}_{\mathrm{v} 0.5} \\
{[\mu \mathrm{m}]}\end{array}$ & $\begin{array}{c}\mathrm{D}_{\mathrm{v0} .9} \\
{[\mu \mathrm{m}]}\end{array}$ & $\begin{array}{c}\mathrm{V}_{<100} \\
{\left[\% \%_{\mathrm{vol}}\right]}\end{array}$ \\
\hline 1 & 015 & 200 & 254 & 526 & 786 & 0.6 \\
2 & 015 & 600 & 161 & 350 & 577 & 2.5 \\
3 & 025 & 400 & 146 & 322 & 551 & 3.7 \\
4 & 025 & 400 & 145 & 319 & 556 & 3.7 \\
5 & 04 & 200 & 213 & 460 & 735 & 1.1 \\
6 & 04 & 600 & 148 & 323 & 544 & 3.3 \\
7 & 06 & 400 & 177 & 391 & 673 & 2.1 \\
8 & 06 & 400 & 173 & 383 & 652 & 2.3 \\
9 & 06 & 400 & 172 & 378 & 642 & 747 \\
11 & 08 & 200 & 210 & 456 & 556 & 2.3 \\
\hline
\end{tabular}


Table 4. Definitive screening model treatment list for the EZKT nozzle

\begin{tabular}{ccccccc}
\hline Run number & Flow rate & $\begin{array}{c}\text { Pressure } \\
{[\mathrm{kPa}]}\end{array}$ & $\begin{array}{c}\mathrm{D}_{\mathrm{v} 0.1} \\
{[\mu \mathrm{m}]}\end{array}$ & $\begin{array}{c}\mathrm{D}_{\mathrm{v} 0.5} \\
{[\mu \mathrm{m}]}\end{array}$ & $\begin{array}{c}\mathrm{D}_{\mathrm{v} 0.9} \\
{[\mu \mathrm{m}]}\end{array}$ & $\begin{array}{c}\mathrm{V}_{<100} \\
{\left[\%{ }_{\mathrm{vol}}\right]}\end{array}$ \\
\hline 1 & 02 & 200 & 139 & 310 & 556 & 4.1 \\
2 & 02 & 600 & 260 & 501 & 735 & 0.5 \\
3 & 03 & 400 & 126 & 275 & 481 & 5.2 \\
4 & 03 & 400 & 149 & 328 & 568 & 3.4 \\
5 & 04 & 200 & 146 & 325 & 568 & 3.6 \\
6 & 05 & 600 & 176 & 391 & 641 & 8.9 \\
7 & 06 & 400 & 105 & 251 & 463 & 3.2 \\
8 & 06 & 400 & 154 & 355 & 602 & 3.1 \\
9 & 06 & 400 & 156 & 359 & 608 & 3.3 \\
10 & 08 & 200 & 153 & 354 & 600 & 814 \\
11 & 08 & 600 & 217 & 482 & & 1.2 \\
\hline
\end{tabular}

Table 5. Definitive screening model treatment list for the AZ nozzle

\begin{tabular}{ccccccc}
\hline Run number & Flow rate & $\begin{array}{c}\text { Pressure } \\
{[\mathrm{kPa}]}\end{array}$ & $\begin{array}{c}\mathrm{D}_{\mathrm{v} 0.1} \\
{[\mu \mathrm{m}]}\end{array}$ & $\begin{array}{c}\mathrm{D}_{\mathrm{v0} .5} \\
{[\mu \mathrm{m}]}\end{array}$ & $\begin{array}{c}\mathrm{D}_{\mathrm{v} 0.9} \\
{[\mu \mathrm{m}]}\end{array}$ & $\begin{array}{c}\mathrm{V}_{<100} \\
{\left[\%{ }_{\mathrm{vol}}\right]}\end{array}$ \\
\hline 1 & 01 & 150 & 82 & 188 & 348 & 16.0 \\
2 & 01 & 500 & 61 & 137 & 251 & 30.2 \\
3 & 02 & 325 & 69 & 159 & 300 & 23.4 \\
4 & 02 & 325 & 69 & 159 & 298 & 23.4 \\
5 & 03 & 150 & 114 & 273 & 477 & 7.1 \\
6 & 04 & 500 & 101 & 199 & 357 & 13.7 \\
7 & 05 & 325 & 101 & 241 & 440 & 9.9 \\
8 & 05 & 325 & 101 & 239 & 434 & 9.7 \\
9 & 05 & 325 & 143 & 337 & 600 & 9.7 \\
10 & 06 & 150 & 100 & 238 & 444 & 3.7 \\
11 & 06 & 500 & & & & 9.9 \\
\hline
\end{tabular}

Table 6. Definitive screening model treatment list for the RS nozzle

\begin{tabular}{ccccccc}
\hline Run number & Flow rate & $\begin{array}{c}\text { Pressure } \\
{[\mathrm{kPa}]}\end{array}$ & $\begin{array}{c}\mathrm{D}_{\mathrm{v} 0.1} \\
{[\mu \mathrm{m}]}\end{array}$ & $\begin{array}{c}\mathrm{D}_{\mathrm{v} 0.5} \\
{[\mu \mathrm{m}]}\end{array}$ & $\begin{array}{c}\mathrm{D}_{\mathrm{v} 0.9} \\
{[\mu \mathrm{m}]}\end{array}$ & $\begin{array}{c}\mathrm{V}_{<100} \\
{\left[\% \%_{\mathrm{vol}}\right]}\end{array}$ \\
\hline 1 & 01 & 310 & 56 & 120 & 222 & 37.0 \\
2 & 02 & 500 & 59 & 130 & 237 & 32.4 \\
3 & 03 & 150 & 102 & 224 & 408 & 9.4 \\
4 & 06 & 325 & 93 & 219 & 419 & 11.8 \\
5 & 06 & 325 & 94 & 223 & 434 & 11.5 \\
6 & 10 & 500 & 107 & 266 & 538 & 8.6 \\
7 & 15 & 150 & 168 & 393 & 768 & 2.2 \\
8 & 15 & 325 & 128 & 330 & 676 & 5.6 \\
9 & 15 & 325 & 126 & 329 & 688 & 5.8 \\
10 & 20 & 150 & 190 & 455 & 908 & 1.5 \\
11 & 20 & 500 & 139 & 361 & 716 & 4.7 \\
\hline
\end{tabular}

\section{Data processing}

All data collected for this work were processed using the $\mathrm{JMP}^{\circledR}$ (Version 11.1.1, 2013 SAS Institute). These $\mathrm{D}_{\mathrm{v} 0.1}$ $\mathrm{D}_{\mathrm{v} 0.5}, \mathrm{D}_{\mathrm{v} 0.9}$, and $\mathrm{V}_{<100}$ were coded as the response variables for each nozzle treatment. A standard least squares analysis was used to fit a model to a second-order response relationship with factors $X_{1}$ [flow rate* (ISO 2005)] and $X_{2}$ (spray pressure) (Eq. 1). The two constants $C_{\text {subi }}$ and $C_{\text {divi }}$ are subtraction and division terms, respectively, used to adjust each $X_{\mathrm{i}}$ input term to a value between -1 and 1 . These values are unique to each nozzle and are dependent on the maximum and minimum flow rate* and spray pressures.

$$
Y=A+B\left(\frac{X_{1}-C_{s u b 1}}{C_{d i v 1}}\right)+C\left(\frac{X_{1}-C_{s u b 1}}{C_{d i v 1}}\right)^{2}+D\left(\frac{X_{2}-C_{s u b 2}}{C_{d i v 2}}\right)+E\left(\frac{X_{1}-C_{s u b 1}}{C_{d i v 1}}\right)\left(\frac{X_{2}-C_{s u b 2}}{C_{d i v 2}}\right)+F\left(\frac{X_{2}-C_{s u b 2}}{C_{d i v 2}}\right)
$$

where:

$Y=$ atomization parameter to be predicted based on input combination of $X_{1}$ through $X_{2}$ (i.e. $D_{\mathrm{v} 0.1}, D_{\mathrm{v} 0.5^{\prime}}$ etc.);

$X_{1}=$ flow rate* (unitless, specific orifice number for each nozzle according ISO 10625 (2005);

$X_{2}=$ spray pressure (bar), $(100 \mathrm{kPa}=1 \mathrm{bar})$;

$\mathrm{C}_{\text {subi }}=$ constant subtraction term;

$C_{\text {divi }}=$ constant dividend term;

$A$ to $F=$ constant coefficients for each term of the prediction expression (unitless and unique for each nozzle). 
Once the final models were developed, the entire operational space, across all combinations of spray pressure and flow rate* was evaluated for droplet size classification (DSC). To determine DSC for each nozzle operational point, the $\mathrm{D}_{\mathrm{v} 0.1}, \mathrm{D}_{\mathrm{v} 0.5}$ values were compared to those from the ASABE reference nozzles with DSC being determined following the methods outline by the standard. To evaluate all operational combinations for each nozzle, a custom FORTRAN (Simply Fortran Ver. 2.15, Approximatrix LLC) code was used. The results were then evaluated to determine overall DSC percentage across each operational space of each nozzle.

\section{Results}

\section{Computational model parameters}

The parameters $A$ through $F$ for each nozzle tested, as well as the $C_{\text {subi }}$ and $C_{\text {divi }}$ for each of the nozzles tested are given in the Appendix in Tables A1 through A6. Using these values and Equation 1, droplet size parameters can be calculated for combinations of flow rate* $\left(X_{1}\right)$ and spray pressure $\left(X_{2}\right)$ that fall within the ranges specified for each nozzle (Table 1). The figure 1 shows an example of calculated atomization characteristics for EZ 11002 nozzle.

\section{EZ nozzle}

The $R^{2}$ values for the response surface models (RSM) were $0.80,0.80,0.75$ and 0.74 for $\mathrm{D}_{\mathrm{v} 0.1,}, \mathrm{D}_{\mathrm{v} 0.5}$, and $\mathrm{D}_{\mathrm{v} 0.9}$ and $\mathrm{V}_{<100}$ curve fits, respectively. Previous models developed for typical flat fan, air induction flat fan, and twin jet flat fan and air induction flat fan nozzles have typically had $R^{2}$ values of 0.92 or higher (Fritz et al. 2016). The flow rate* and pressure were significant factors for $\mathrm{D}_{\mathrm{v} 0.1}$ ( $\mathrm{p}$ values of 0.0246 and 0.0420 , respectively). However, flow rate ${ }^{*}$ by flow rate*, pressure by pressure, and flow rate* by pressure effect were not significant. Similar results were seen with $\mathrm{D}_{\mathrm{v} 0.5}$ with flow rate ${ }^{*}$ and pressure being significant ( $p$ values of 0.0226 and 0.0354 , respectively) and the other parameters not significant. As observed at the $\mathrm{D}_{\mathrm{v} 0.9}$ only pressure was a significant factor $(p=0.0238)$ and for $V_{<100}$ none of the parameters were significant. The actual droplet size data shows that these results are not surprising as $\mathrm{D}_{\mathrm{v} 0.1}$ data ranges from $\varnothing 120$ to $220 \mu \mathrm{m}$ across all flow rate ${ }^{*}$ and pressure combinations, while $\mathrm{D}_{\mathrm{v} 0.5}$ data ranges from $\varnothing 263$ to $439 \mu \mathrm{m}, \mathrm{D}_{\mathrm{v} 0.9}$ data ranges from $\varnothing 484$ to $814 \mu \mathrm{m}$ and $V_{<100}$ ranges from 1.2 to $6 \%$ vol . While these ranges are fairly typical some of the flow rate* and pressure combinations that would be expected to be quite different are very similar. For example data from the 015 flow rate* at $390 \mathrm{kPa}$ shows $\mathrm{D}_{\mathrm{v} 0.1}, \mathrm{D}_{\mathrm{v} 0.5}$, and $\mathrm{D}_{\mathrm{v} 0.9}$ and $\mathrm{V}_{<100}$ values of $\varnothing 170,384,707 \mu \mathrm{m}$, and $2.7 \%{ }_{\mathrm{vol}}$, respectively. Similarly for the 08 flow rate ${ }^{*}$ at $600 \mathrm{kPa}$ we see values of $\varnothing 165,382$, $653 \mu \mathrm{m}$ and $2.8 \%_{\mathrm{vol}}$ for $\mathrm{D}_{\mathrm{v} 0.1}, \mathrm{D}_{\mathrm{v} 0.5}$, and $\mathrm{D}_{\mathrm{v} 0.9}$ and $\mathrm{V}_{<100}$, respectively. Similar data is seen with the 06 flow rate* at $430 \mathrm{kPa}\left(\varnothing 169,384,642 \mu \mathrm{m}\right.$, and $2.2 \%$ vol for $\mathrm{D}_{\mathrm{v} 0.1}, \mathrm{D}_{\mathrm{v} 0.5^{\prime}}$ and $\mathrm{D}_{\mathrm{v} 0.9}$ and $\mathrm{V}_{<100}$ respectively). With little change observed across different flow rate* and pressures, the RSM type prediction models did not result in high level fits.

\section{EZK nozzle}

The $R^{2}$ values for the RSM were $0.83,0.83,0.82$ and 0.73 for $\mathrm{D}_{\mathrm{v} 0.1}, \mathrm{D}_{\mathrm{v} 0.5}$, and $\mathrm{D}_{\mathrm{v} 0.9}$ and $\mathrm{V}_{<100}$ curve fits, respectively. These models showed only marginally better fits than the EZ design. Only pressure was a significant factor for $D_{v 0.1}$ ( $p$ value of 0.0073 ). Similar results were seen with $\mathrm{D}_{\mathrm{v} 0.5^{\prime}}$ $\mathrm{D}_{\mathrm{v} 0.9}$, and $\mathrm{V}_{<100}$ with only pressure being significant for both ( $p$ values of $0.0066,0.0061$, and 0.0197 respectively). The droplet size data supports these results. Regardless of flow rate* by droplet size by spray comparison shows $D_{v 0.1}$ values of $\varnothing 253,213$ and $210 \mu \mathrm{m}$ for the $200 \mathrm{kPa}$ spraying pressure, $\varnothing 146,145,177,173$ and $172 \mu \mathrm{m}$ for the $400 \mathrm{kPa}$ and finally $\varnothing 161,148$ and $139 \mu \mathrm{m}$ for the $600 \mathrm{kPa}$. These trends hold for $\mathrm{D}_{\mathrm{v} 0.5}, \mathrm{D}_{\mathrm{v} 0.9}$ and $\mathrm{V}_{<100}$ as well.

\section{EZKT nozzle}

The $R^{2}$ values for the RSM were $0.81,0.78,0.78$ and 0.52 for $D_{v 0.1}, D_{v 0.5^{\prime}}$ and $D_{v 0.9}$ and $V_{<100}$ curve fits, respectively. These models showed lesser fits than either the EZ or EZK nozzle designs. Like the EZK design, only pressure was a significant factor for $\mathrm{D}_{\mathrm{v} 0.1}, \mathrm{D}_{\mathrm{v} 0.5^{\prime}}$ and $\mathrm{D}_{\mathrm{v} 0.9}$ ( $\mathrm{p}$ value of $0.0219,0.0280$, and 0.0380 , respectively). However, none of the factors were significant predictors of $\mathrm{V}_{<100}$. From the droplet size data, we can see similar trends to the EZK nozzle, though not with quite the same level of strength (as indicated by the higher $\mathrm{p}$ values). At the $200 \mathrm{kPa}, \mathrm{D}_{\mathrm{v} 0.1}$ values were $\varnothing 139,146$ and $153 \mu \mathrm{m}$, while at $400 \mathrm{kPa}$ were $\varnothing 126,146,105,154$ and $156 \mu \mathrm{m}$, and at $600 \mathrm{kPa}$ were $\varnothing 260,176$ and $271 \mu \mathrm{m}$. Similar trends are seen with $\mathrm{D}_{\mathrm{v} 0.5}$ and $\mathrm{D}_{\mathrm{v} 0.9}$. This nozzle is not typical compared with most hydraulic nozzles as an apparent increase in droplet size occurred with an increase in pressure, which is also indicated by the decrease in $\mathrm{V}_{<100}\left(0.5\right.$ to $1.9 \%_{\mathrm{vol}}$ at $600 \mathrm{kPa}$ compared to 3.1 to $8.8 \%$ vol at 200 and $400 \mathrm{kPa}$ ).

\section{AZ nozzle}

The AZ nozzle showed significantly better models fits with $R^{2}$ values of 0.99 for $\mathrm{D}_{\mathrm{v} 0.1}, \mathrm{D}_{\mathrm{v} 0.5}$, and $\mathrm{D}_{\mathrm{v} 0.9}$ and 0.98 for $\mathrm{V}_{<100}$. Both flow rate* and pressure were significant factors for all droplet size metrics with their interaction and square effects significant in most cases (at the $\alpha=0.05$ level).

\section{RS nozzle}

The RS nozzle also showed good models fits with $R^{2}$ values of 0.99 for $\mathrm{D}_{\mathrm{v} 0.1}, \mathrm{D}_{\mathrm{v} 0.5}$, and $\mathrm{D}_{\mathrm{v} 0.9}$ and 0.92 for $\mathrm{V}_{<100}$. Again, flow rate* and pressure were significant factors for all droplet size metrics with their interaction and square effects being significant in most cases (at the $\alpha=0.05 \mathrm{lev}$ el). The RS nozzle represents that largest span in flow rate $^{*}$ of those tested in the work and the trends in droplet size are much more obvious in its data with the smallest flow rate* showing much smaller droplet sizes and greater fines that the largest flow rate*. One of the exceptions with respect to the significant factors was the flow rate* by pressure effect ( $p$ values ranging from 0.1 to 0.38 ). This is readily apparent in the droplet size data looking at the 20 orifice (flow rate ${ }^{*}$ ) data where both the maximum and 
MMAT Nozzle Models

STEP 1: SELECT NOZZLE MODEL USING PULL DOWN MENU

\begin{tabular}{|lcc}
\hline & STEP 2: SELECT NOZZLE OPERATING SETTINGS FROM PULL DOWN MENUS BELOV \\
Acceptable Ranges: & Flow rate* (ISO 10625) & Pressure range \\
& 015 to 08 & 1 to 6 bar \\
2 & 2 \\
\hline
\end{tabular}

\begin{tabular}{|c|c|}
\hline \multicolumn{2}{|c|}{ CAUTION: Do not enter or clear data in the cells in this box! } \\
\hline$D_{\mathrm{v} 0.1}=161 \mu \mathrm{m}$ & $=$ Droplet size $-10 \%$ of the spray volume is in droplets below $D_{v 0.1}$ \\
\hline$D_{\mathrm{v} 0.5}=375 \mu \mathrm{m}$ & $=$ Volume median diameter $\left(\mathrm{VMD}=\mathrm{D}_{\mathrm{v} 0.5}\right)$ \\
\hline $\mathrm{D}_{\mathrm{v} 0.9}=729 \mu \mathrm{m}$ & $=$ Droplet size $-90 \%$ of the spray volume is in droplets below $D_{\text {v0.9 }}$ \\
\hline $\mathrm{RS}=1,51$ & = Relative Span \\
\hline$V_{<100}=2,72 \%$ vol & $=$ Percentage of spray volume in droplets below $\varnothing 100 \mu \mathrm{m}$ \\
\hline $\mathrm{DSC}_{\mathrm{v} 0.1}=$ COARSE & $=$ Droplet Size Classification based on $D_{\mathrm{v} 0.1}$ \\
\hline $\mathrm{DSC}_{\mathrm{v} 0.5}=$ COARSE & $=$ Droplet Size Classification based on $\mathrm{D}_{\mathrm{v} 0.5}(\mathrm{VMD})$ \\
\hline DSC = COARSE & $=$ ANSI/ASAE S572.1 (ASABE 2009) Droplet Size Classification (DSC) \\
\hline
\end{tabular}

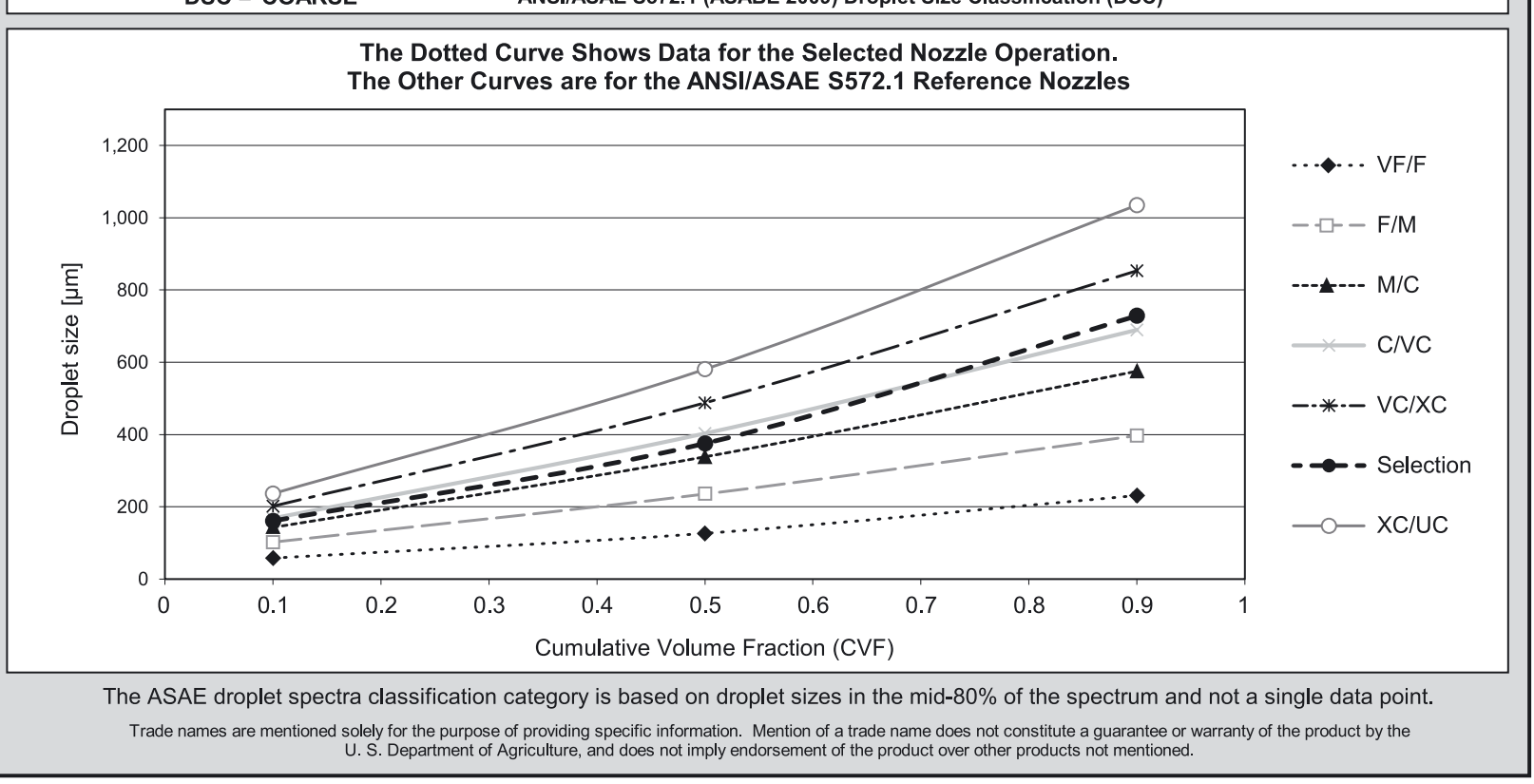

Fig. 1. Excel user interface for MMAT nozzles evaluated as part of this study; VF - Very Fine; F - Fine; M - Medium; C - Coarse; VC - Very Coarse; XC - Extremely Coarse; UC - Ultra Coarse

minimum pressures were evaluated. While droplet size trends were as expected (smaller at higher pressures) the difference is not as dramatic as compared to droplet size for the 03 flow rate* at the same pressure.

\section{Integration into Excel based user interface}

The developed models were integrated into an automated user interface (UI) using Microsoft Excel (Fig. 1). The UI requires the user to select the nozzle type followed by selecting the flow rate ${ }^{*}$ and spray pressure combination for which droplet size data is desired. Along with returning the model calculated for $\mathrm{D}_{\mathrm{v} 0.1}, \mathrm{D}_{\mathrm{v} 0.5}$, and $\mathrm{D}_{\mathrm{v} 0.9}$ and $\mathrm{V}_{<100}$, the data is compared to the ASAE/ANSI S572.1 (ASABE 2009) to determine droplet size classification.

\section{Discussion/Conclusions}

Actually don't exist any advising system for atomization characteristics unified with PPP labels. A structured evaluation method was proposed and conducted to evaluated, and ultimately develop a DSS, for agricultural spray nozzles. Measurements of the droplet size spectrum were made for a variety of MMAT nozzles and used to develop the proposed DSS. Using the proposed response surface experimental design method allows for the creation of a computational model which provides droplet size data for a given spray nozzle based on the operational settings. Using the developed model, application treatments can be setup to account for specific scenarios (weather, crop, pest, tank mix, technique) in the field to follow Integrated Pest Management (IPM) requirements (obligation in EC28 since January 2015). The developed models are readily available for use with common spreadsheet software. While the data in this manuscript is limited to a select number of MMAT nozzles, the method proposed can be readily used for any agrochemical hydraulic spray nozzle. This model based method can be professional support for advisors in crop protection and field sprayer operators adequate to different field scenarios. The activation of this 
model on website, as instrument for increase of crop protection safety and efficiency, will be successful and for free accessed. An enlargement of this model by nozzles from other manufacturers is possible on similar way.

Thanks analyze of tested nozzle set, could be concluded, that the twin jet flat fan air induction nozzle (EZKT) that is not typical with most hydraulic nozzles is an apparent increase in droplet size with an increase in pressure which is also indicated by the decrease sprayed liquid volume in size below $\varnothing 100 \mu \mathrm{m}\left(\mathrm{V}_{<100}\right)$.

The offered option of DSS confirmed big potential of spray characteristics to improve safety and efficiency of PPP application, on very easy and cheap way. Further research according proposed solution, and implementation is possible.

\section{Acknowledgements}

The research partially was done during projects 598/BNI/ DPP/11 and 606/BNI/DPP/11 from PARP (Polish Agency for Enterprise Development).

\section{References}

ANSI/ASAE S572.1. 2009. Spray Nozzle Classification by Drop Spectra. The American Society of Agricultural Engineers, American Society of Agricultural and Biological Engineers (ASABE) Standards, St. Joseph, MI, USA, 4 pp.

American Society of Agricultural and Biological Engineers (ASABE) 2012. Terminology and Definitions for Agricultural Chemical Application. ASABE Standards S327.3 (R2012), St. Joseph, MI, USA, 6 pp.

Czaczyk Z. 2012a. Spray classification for selected flat fan nozzles. Journal of Plant Protection Research 52 (1): 180-183.

Czaczyk Z. 2012b. Working characteristics of selected flat fan nozzles for protection of field crops. Journal of Research and Applications in Agricultural Engineering 57 (2): 31-40. Available on: http://www.pimr.poznan.pl/ biul/2012_2_6CZ2.pdf [Accessed: November 11, 2015]

Czaczyk Z. 2013. Jakość rozpylenia cieczy jako element doradczy decydujący o efektywności i bezpieczeństwie ochrony roślin. [Spraying characteristics as advising factor, influenced effectiveness and safety of plant protection]. Zagadnienia Doradztwa Rolniczego 71 (1): 30-44.

Czaczyk Z., Fritz B.K., Hoffmann W.C. 2014. Problems with determination of spraying characteristics (a review). Aspects of Applied Biology 122, International Advances in Pesticide Application: 405-410.

Czaczyk Z., Gnusowski B. 2007. Comparison of fungicide residues in apple flesh depending on spraying categories. Annales of the University of Craiova XXXVII(A): 554-557.

Czaczyk Z., Szulc T. 2012. Working and production characteristics of selected flat fan nozzles. Journal of Research and Applications in Agricultural Engineering 57 (2): 52-59.

Doble S.J., Matthews G.A., Rutherford I., Southcombe E.S.E. 1985. A System for Classifying Hydraulic Nozzles and Other Atomizers into Categories of Spray Quality. p. 11251133. In: British Crop Protection Conference Weeds 9A-5, Brighton Metropole, UK, 18-21 November 1985, 1300 pp.

Dodge L.G. 1987. Comparison of performance of drop-sizing instruments. Applied Optics 26 (7): 1328-1341.
Dorr G.J., Hewitt A.J., Adkins S.W., Hanan J., Zhang H., Noller B. 2013. A comparison of initial spray characteristics produced by agricultural nozzles. Crop Protection 53: 109-117.

Douzals J.P. 2012. Asymmetric classification of drift reducing nozzles considering frontal or lateral wind conditions. Proceedings of CIGR - Agiculture and Engineering Meeting, Valencia, Spain, 8-12 July 2012, 4 pp.

Fritz B.K., Hoffmann W.C., Bagley W.E., Kruger G.R., Czaczyk Z., Henry R.S. 2014a. Measuring droplet size of agricultural spray nozzles - measurement distance and airspeed effects. Atomization Sprays 24 (9): 747-760.

Fritz B.K., Hoffmann W.C., Czaczyk Z., Bagley W., Kruger G., Henry R. 2012. Measurement and classification methods using the ASAE S572.1 reference nozzles. Journal of Plant Protection Research 52 (4): 452-462.

Fritz B.K., Hoffmann W.C., Kruger G.R., Henry R.S., Hewitt A., Czaczyk Z. 2014b. Comparison of drop size data from ground and aerial application nozzles at three testing laboratories. Atomization Sprays 24 (2): 181-192.

Fritz B.K., Hoffman W.C., Anderson J. 2016. Response surface method for evaluation of the performance of agricultural application spray nozzles. p. 61-76. In: "Pesticide Formulation and Delivery Systems." Vol. 35. (G.R. Goss, ed.). ASTM International, West Conshohocken, PA, USA. DOI: 10.1520/ STP158720140100

Gajtkowski A. 1985. Dobór parametrów pracy rozpylaczy i opryskiwaczy polowych. [Investigations and selection of operations parameters for sprayers used in field spraying]. Roczniki Akademii Rolniczej w Poznaniu, Rozprawy Naukowe 151, 95 pp. (in Polish)

Giles D.K., Downey D., Squire L. 2005. Transient droplet size spectra from trigger sprayers dispensing aqueous solutions. Transactions of the American Society of Agricultural and Biological Engineers (ASAE) 48 (1): 63-72.

Hammond D.C. Jr. 1981. Deconvolution technique for line-ofsight optical scattering measurements in axisymmetric sprays. Applied Optics 20 (3): 493-499.

Hewitt A.J. 1997a. Droplet size and agricultural spraying, Part 1: Atomization, spray transport, deposition, drift and droplet size measurement techniques. Atomization Sprays 7 (3): 235-244.

Hewitt A.J. 1997b. Spray drift task force study No. A95-010, Miscellaneous Nozzle Study, EPA MRID No. 44310401.

ISO 10625. 2005. Equipment for Crop Protection. Sprayer Nozzles. Colour Coding for Identification. International Organization for Standardization, $12 \mathrm{pp}$.

ISO 8169. 1984. Equipment for Crop Protection - Sprayers - Connecting Dimensions for Nozzles and Manometers. International Organization for Standardization, $3 \mathrm{pp}$.

Kirk I.W. 2007. Measurement and Prediction of Atomization Parameters from Fixed-wing Aircraft Spray Nozzles. Transactions of the American Society of Agricultural and Biological Engineers (ASABE) 50 (3): 693-703.

Matthews G.A. 2000. Pesticide Application Methods. 3rd ed. Wiley-Blackwell, Oxford, UK, 448 pp.

Miller P.C.H., Tuck C.R. 2005. Factors Influencing the Performance of Spray Delivery Systems: A Review of Recent Developments. Journal of ASTM International 2 (6): 1-13.

Tishkoff J.M. 1984. Spray characterization: Practices and requirements. Optical Engineering 23 (5): 557-560. 


\section{Appendix}

Table A1. Subtraction and division terms (Eq. 1) used to convert factor inputs to model coded inputs (-1 to 1$)$

\begin{tabular}{crrrr}
\hline \multirow{2}{*}{ Nozzle design } & \multicolumn{2}{c}{$X_{1}-$ Flow rate* $^{*}$} & \multicolumn{2}{c}{$X_{2}-$ Pressure } \\
\cline { 2 - 5 } \cline { 3 - 5 } & $C_{\text {sub1 }}$ & $C_{\text {div1 }}$ & $C_{\text {sub2 }}$ & $C_{\text {div2 }}$ \\
\hline EZ & 4.75 & 3.25 & 4.25 & 1.75 \\
EZK & 4.75 & 3.25 & 4.00 & 2.00 \\
EZKT & 5.00 & 3.00 & 4.00 & 2.00 \\
AZ & 3.50 & 2.50 & 3.25 & 1.75 \\
RS & 10.90 & 9.50 & 3.25 & 1.75 \\
\hline
\end{tabular}

Table A2. EZ model coefficients

\begin{tabular}{ccccccc}
\hline & \multicolumn{3}{c}{ Coefficient terms } \\
\cline { 2 - 6 } Coefficient & intercept (A) & flow rate* $(\mathrm{B})$ & $\begin{array}{c}\text { flow rate* by } \\
\text { flow rate* }(\mathrm{C})\end{array}$ & pressure (D) & $\begin{array}{c}\text { flow rate* by } \\
\text { pressure (E) }\end{array}$ & $\begin{array}{c}\text { pressure by } \\
\text { pressure (F) }\end{array}$ \\
\hline $\mathrm{D}_{\mathrm{v} 0.1}$ & 177.0940 & 22.54702 & 0.717130 & -17.4592 & -4.58369 & -9.33963 \\
$\mathrm{D}_{\mathrm{v} 0.5}$ & 397.1480 & 51.43177 & 4.188014 & -40.9629 & -1.31967 & -19.62580 \\
$\mathrm{D}_{\mathrm{v} 0.9}$ & 667.2766 & 46.26003 & 35.892080 & -73.9671 & 18.98021 \\
$\mathrm{~V}_{<100}$ & 2.17296 & -1.11595 & 0.407345 & 0.965689 & -0.446 & 0.629628 \\
\hline
\end{tabular}

Table A3. EZK model coefficients

\begin{tabular}{ccccccc}
\hline \multirow{2}{*}{ Coefficient } & \multicolumn{5}{c}{ Coefficient terms } & \\
\cline { 2 - 7 } \cline { 2 - 6 } & intercept (A) & flow rate* $(\mathrm{B})$ & $\begin{array}{c}\text { flow rate* by } \\
\text { flow rate* }(\mathrm{C})\end{array}$ & pressure (D) & $\begin{array}{c}\text { flow rate* by } \\
\text { pressure (E) }\end{array}$ & $\begin{array}{c}\text { pressure by } \\
\text { pressure (F) }\end{array}$ \\
\hline $\mathrm{D}_{\mathrm{v} 0.1}$ & 162.1409 & -4.8667 & 1.176058 & -37.6311 & 4.615500 & 24.1271 \\
$\mathrm{D}_{\mathrm{v} 0.5}$ & 358.5630 & -4.0688 & -1.072300 & -76.0660 & 6.359170 & 46.2174 \\
$\mathrm{D}_{\mathrm{v} 0.9}$ & 616.2310 & 14.8019 & -3.162700 & -98.1670 & 4.042849 & 44.57401 \\
$\mathrm{~V}_{<100}$ & 2.731582 & 0.070268 & 0.3173 & 1.16209 & 0.22939 & -0.79334 \\
\hline
\end{tabular}

Table A4. EZKT model coefficients

\begin{tabular}{ccccccc}
\hline \multirow{2}{*}{ Coefficient } & \multicolumn{5}{c}{ Coefficient terms } & \\
\cline { 2 - 6 } & intercept (A) & flow rate* $(\mathrm{B})$ & $\begin{array}{c}\text { flow rate* by } \\
\text { flow rate* }(\mathrm{C})\end{array}$ & pressure (D) & $\begin{array}{c}\text { flow rate* by } \\
\text { pressure (E) }\end{array}$ & $\begin{array}{c}\text { pressure by } \\
\text { pressure (F) }\end{array}$ \\
\hline $\mathrm{D}_{\mathrm{v} 0.1}$ & 130.7588 & -4.86670 & 28.89528 & 35.78791 & 4.61550 & 24.12710 \\
$\mathrm{D}_{\mathrm{v} 0.5}$ & 302.6600 & 11.24138 & 47.29411 & -76.06600 & 6.35917 & 46.21740 \\
$\mathrm{D}_{\mathrm{v} 0.9}$ & 529.8681 & 34.00733 & 68.49176 & -98.16700 & 12.13131 & 76.86829 \\
$\mathrm{~V}_{<100}$ & 4.917808 & 0.13325 & 0.3173 & 1.21639 & 0.22939 & -2.06758 \\
\hline
\end{tabular}

Table A5. AZ model coefficients

\begin{tabular}{|c|c|c|c|c|c|c|}
\hline \multirow[b]{2}{*}{ Coefficient } & \multicolumn{5}{|c|}{ Coefficient terms } & \multirow[b]{2}{*}{$\begin{array}{l}\text { pressure by } \\
\text { pressure }(F)\end{array}$} \\
\hline & intercept (A) & flow rate* (B) & $\begin{array}{l}\text { flow rate* by } \\
\text { flow rate* }(C)\end{array}$ & pressure (D) & $\begin{array}{l}\text { flow rate* by } \\
\text { pressure }(E)\end{array}$ & \\
\hline $\mathrm{D}_{\mathrm{v} 0.1}$ & 87.0528 & 25.4032 & -5.1014 & -16.6774 & -5.6825 & 14.8311 \\
\hline $\mathrm{D}_{\mathrm{v} 0.5}$ & 205.6732 & 63.7931 & -14.0528 & -41.7462 & -12.0242 & 33.3254 \\
\hline $\mathrm{D}_{\mathrm{v} 0.9}$ & 372.7312 & 111.8857 & -9.4892 & -69.8307 & -14.7567 & 47.6947 \\
\hline $\mathrm{V}_{<100}$ & 14.7441 & -9.1147 & 4.3455 & 5.0899 & -1.9917 & -4.1195 \\
\hline
\end{tabular}

Table A6. RS model coefficients

\begin{tabular}{ccccccc}
\hline \multirow{2}{*}{ Coefficient } & \multicolumn{5}{c}{ Coefficient terms } & \\
\cline { 2 - 6 } & intercept (A) & flow rate $^{*}(\mathrm{~B})$ & $\begin{array}{c}\text { flow rate* by } \\
\text { flow rate* }(\mathrm{C})\end{array}$ & pressure (D) $^{\text {flow rate }}$ & $\begin{array}{c}\text { flow } \\
\text { pressure (E) }\end{array}$ & $\begin{array}{c}\text { pressure by } \\
\text { pressure (F) }\end{array}$ \\
\hline $\mathrm{D}_{\mathrm{v} 0.1}$ & 112.4252 & 45.1769 & -11.2912 & -20.7194 & -3.7683 & 16.0732 \\
$\mathrm{D}_{\mathrm{v} 0.5}$ & 281.1691 & 127.5347 & -32.0592 & -38.7040 & -4.3229 & 26.9281 \\
$\mathrm{D}_{\mathrm{v} 0.9}$ & 569.6825 & 274.3293 & -73.3612 & -68.6275 & -14.6819 & 35.4328 \\
$\mathrm{~V}_{<100}$ & 6.7168 & -11.4429 & 14.4494 & 4.8463 & -4.8265 & -4.7989 \\
\hline
\end{tabular}

